\title{
Necessary Requirements for Implementation of Financial Reform in the Iranian Health Sector
}

\author{
Mohammad Javad Kabir, ${ }^{1,2}$ Masoud Abolhallaje, ${ }^{3}$ Peivand Bastani, ${ }^{4, *}$ and Anahita Keshavarzi ${ }^{2}$ \\ ${ }^{1}$ Health Management and Social Development Research Center, Golestan University of Medical Sciences, Gorgan, Iran \\ ${ }^{2}$ Deputy of Health Insurance Services, Strategic Purchasing Office, Iranian Health Insurance Organization (IHIO), Tehran, Iran \\ ${ }^{3}$ Budget and Performance Monitoring, Ministry of Health and Medical Education, Tehran, Iran \\ ${ }^{4}$ Assistant Professor of Healthcare Management, Health Human Resources Research Center, School of Management and Medical Informatics, Shiraz University of Medical \\ Sciences, Shiraz, Iran \\ "Corresponding author: Peivand Bastani, Assistant Professor of Healthcare Management, Health Human Resources Research Center, School of Management and Medical \\ Informatics, Shiraz University of Medical Sciences, Shiraz, Iran. Tel: +98-9173015667, E-mail: bastanip@sums.ac.ir
}

Received 2016 August 21; Revised 2016 November 06; Accepted 2016 November 18.

\begin{abstract}
Background: A four-step map of financial reform in Iranian health sector has been proposed with the aim of increasing efficiency and resource allocation.

Objectives: This study was conducted to investigate the necessary requirements to establish the three last phases of this reform in Iran, during year 2015.

Methods: A qualitative study in the form of framework analysis approach was conducted. An interview guide was used for interviewing 22 purposefully selected experts individually in a semi-structured format and data were saturated at this level. Data were analyzed using five-stage method of framework analysis (familiarization, identifying a thematic framework, indexing, charting and mapping, and interpretation) using the Atlas Ti software, by two experts with no conflicts of interest.

Results: Six main themes and 18 sub-themes were extracted that introduced six groups of requirements including economic, functional, legal, organizational, informational, and educational, as the most vital needs for conducting financial reform in the Iranian health system.

Conclusions: Findings showed that there are numerous problems with conducting financial reform despite spending a decade after its implementation in the Iranian health system. Therefore, the current results as well as planning to recognize and promote the modifiable parts in this field might be beneficial for policy-makers of the country to make a definite plan for revising this process with drafting a long-term perspective and a tailored context for complete and successful executing.
\end{abstract}

Keywords: Financial Reform, Health Care System, Accrual Accounting, Activity Based Cost, Operational Budgeting

\section{Background}

Experts introduced the main factors of reform in the health system as follows, increasing health care costs, increasing public expectations, resources limitation and increasing public demand from the government due to poor governance, corruption and inefficiency of power, and bureaucratic inhibitors (1). Moreover, there are other factors that forced developing countries to reform their health system, including focusing on decision-making, poor allocation efficiency, poor technical performance, high cost of patients for receiving health services, poor quality of service and bad performance of the health system staff (2). Other studies categorized the main reform content of the health system to 4 sections comprised of changes in methods of funding health care, changes in the allocation of resources in the health system, changes in the method or the supply of health services and justice (3); three of the four aforementioned sections are classified as financial reform.

In the Iranian health system, the Ministry of Health, as custodian of public health, is an organization with responsibilities for explaining policies and strategies, influencing the behavior of internal and external actors, guiding and developing national health activities and general supervision (4). In the past few years, evidence showed a lack of reliable information and consequently poor decision that were made on the basis of information by this ministry; in addition, disjunction of information in terms of human, logistics, budget resources and financial systems in the health system has led to many challenges that make financial reform necessary in the Iranian health system (5). According to the criticism of the traditional system, emphasis of the Fourth Development Plan, financial and transactional regulations in all Universities and Medical schools across the country, public accounting and civil service management regulations as well as the board law has accentuated on financial reform in the health system (6).

With regards to the emphasis of numerous documents

Copyright (c) 2017, Journal of Health Scope. This is an open-access article distributed under the terms of the Creative Commons Attribution-NonCommercial 4.0 International License (http://creativecommons.org/licenses/by-nc/4.0/) which permits copy and redistribute the material just in noncommercial usages, provided the original work is properly cited. 
and also the ministry's operation span that is responsible for the financial management of more than 50 Universities, about 600 governmental hospitals, and more than 4000 urban and rural health centers (7), the financial reform in the health system is suggested in a four-stage process aimed at establishing a system of performance-based or results-based management that stresses on improving efficiency, effectiveness, and operational accountability in the public sector with increased precision in the management of resources instead of a focus on inputs (8). These four stages are as follows:

Establishment of accrual accounting rather than cash accounting: Cash accounting registers receipts, payments, and cash balances at the time of cash exchange. Then, financial statement based on cash accounting shows traditionally the sources of cash and cash expenditure allocation and also compares it with expenditures; while, the use of this system is not effective in gaining benefit from public resources by the government (9).

Establishment and development of accounting cost or activity based cost: Cost is a very important factor in the management process to measure the cost of production and also to control the cost of materials, salary and other production using industrial accounting. This method is not merely limited to the manufacturing sector, and other parts including banks, insurance companies, major shops, transportation companies, airlines, Universities, and hospitals are applying this strategy to improve efficiency (10).

Establishment of performance-based budgeting: This kind of funding is a system of planning, budgeting, and evaluation that emphasizes on the relationship between budget and expected results. Its privileges can be mentioned as increased accountability based on results, improved performance management as well as allocation process (11).

Cost and efficiency management provide policymakers, senior and performance managers and decisionmakers with optimal decision model after the disclosure of financial information (12).

Despite the importance of the aforementioned reform and the critical role of accrual basis in determining the price of services and operational budgeting to meet the needs of the community, these reforms need a comprehensive approach to achieve the assumption presented in the law of fourth and fifth plans for socio-economic development (13).

\section{Objectives}

As stage I of financial reform has completely been implemented in the Iranian health system and all related parts of the Ministry of Health during year 2013, it is obvious that conducting the other 3 phases of financial reform in the country can significantly improve the provision, facilitation and clarity of the process. Thus, this study aimed at investigating the requirements for applying phases 2, 3, and 4 of financial reform in the health system of Iran.

\section{Methods}

This study was a qualitative study using framework analysis approach aimed to explore necessary requirements to implement financial reform in the Iranian health system in phases of 2, 3, and 4 from experts and policymakers point of view, during years 2013 to 2014 . The population study consisted of all of key informants and experts in the field, including ministry of health at a high level (ministers after the revolution), specialists of the ministry of health in the middle management levels (vice president of development and director of the budget), main experts of strategic planning and eligible people of health commission of parliament that were selected based on the purposeful sampling technique.

To achieve this, two former ministers of health, four vice chancellors of development and management of resources, four chiefs of budget and two employees of health commission of the parliament, who had roles in the past years from 1991 to 2014 years, were included. Also more interviewing was done using snowball sampling with a person, who had similar responsibilities because of failure to reach saturation level; saturated data was achieved after 22 interviews. To collect data, qualitative and semistructured interviewing was used. To design the interviewing guide, a literature review and in-depth interviewing was conducted apart from interviewing with two experts in the field of financial health. The final version of the interviewing guide was prepared by the research team and the approved version was used for 3 sample interviews with 3 financial experts that were not included in the main sample for assuring the validity of the questions. This guide was modifiable during the interviewing; however, the researcher purposefully selected key informants and all samples responded to all questions of the interviewing guide. Before conducting the interviewing, all samples were previously coordinated with telephone or in-person. Informed consent was obtained from all participants after describing the study goals and objectives. In addition, all the samples were told that they could leave the study at any time. All of the participants were assured that the audio files and text were completely anonymous and coded in a safe place.

In order to ensure accurate and high quality interviewing as well as increased accuracy and confidentiality of 
content, the researcher tried to hold the meetings in a calm and safe environment. The duration of each interviewing was between 45 and 55 minutes, depending on the interest and tolerance of respondents. To prevent probable problems, all interviewing was recorded using 2 electronic devices and the researcher noted all the facial expressions and body gestures.

To analyze the results of this phase, framework analysis of qualitative data was used that consisted of 5 steps (14):

1- Familiarization: at this stage, a summary of the content of communication was designed for each interviewing.

2- Identifying a thematic framework: at this stage, a thematic framework was designed based on the objectives of the study, previous surveys, interviewing and thematic guides and was debated by the research team in two common sessions and, finally, were reviewed using the literature rewritten through interviews.

3- Indexing: to do this, researchers primarily indexed the interviewing by using the Atlas Ti software, and different parts of interviewing were indexed in accordance with thematic relation through one or more codes. These codes were reviewed in several times by the two researchers and were finally debated by all the research team.

4- Charting: at this stage, comments of interviewees on each subject were compared using analytical tables and the relationship between topics and sub-topics (main and sub-themes) were also detected and analyzed.

5- Mapping and Interpretation: at the final phase, all topics were interpreted using Atlas Ti in a way that all interviewing was conducted by informed researchers. All data obtained by researcher's colleagues were also confirmed. Interviewing files were entered in the form of words in the Atlas Ti software and analyzed by the researcher and his team. To ensure the reliability between coders, two members of the research team that had no conflict of interest with the subject coded the two texts of interviews, debated on conflicts, and solved them. In order to obtain feedback from participants about the interpretation of the data and ensure that their views were properly presented, findings were sent to them, and their feedback was used to improve the interpretation of data.

In order to achieve validity and reliability of qualitative research, authors tried to validate the topic guide of the interviews through three pilot interviews along with applying member check, peer check, and expert check. In this regard all the transcriptions were transformed for the participants and after their confirmation, the codes were checked by all the research members and some experts of budget and performance monitoring department of Mohme. Using different participants and trying to probe the topic guide also helped triangulation of the study de- sign.

\section{Results}

The current findings were obtained from interviewing 22 experts, who worked as part of the health system, health financial system, health accounting, and health budgeting. Table 1 shows the frequency of interviewees based on their current or previous organizational position.

Table 1. Demographic Characteristics of Interviewees Based on Their Organizational Position

\begin{tabular}{|lcc|}
\hline $\begin{array}{l}\text { Current and Previous Organizational } \\
\text { Position }\end{array}$ & Number & Percentage \\
\hline $\begin{array}{l}\text { The minister of Health } \\
\begin{array}{l}\text { Vice-Chancellor of development and } \\
\text { management of university }\end{array}\end{array}$ & 2 & 9 \\
\hline $\begin{array}{l}\text { Member of health and medicine of } \\
\text { commission of parliament }\end{array}$ & 2 & 9 \\
\hline $\begin{array}{l}\text { General manager of budgeting of ministry } \\
\text { of health }\end{array}$ & 4 & 18 \\
\hline $\begin{array}{l}\text { Financial controller of ministry of health } \\
\text { Ministry representative of economy and } \\
\text { finance }\end{array}$ & 2 & 9 \\
\hline Expert accountants & 2 & 9 \\
\hline Member of the new financial system & 2 & 9 \\
\hline Total & 4 & 18 \\
\hline
\end{tabular}

Analysis of the interviews resulted in 6 themes (main theme) and 18 sub-scales as reported in Table 2.

\subsection{Economic Requirements}

Interviewees believed that most priorities of the government are improving quality of services, efficient use of sources and existing capabilities, providing contexts to standardize governmental services, increasing motivation of staff and managers, and providing them with authorities and use of controlling activities instead of controlling process and, in brief, need for budgeting in governmental institution due to economic liberalization and rules and regulations standardization. In this regard, an interviewee proposed that:

"One of the changes that occurred in the governmental accounting system could have been caused by significant development in governmental responsibilities, changes in government programs and weak efficient informational system..." (p2).

Also, according to the participant's opinions, budgetary control and financial management of governmental institutions in line with annual confirmed budget has been regarded in the recent years by the government and 
Table 2. Requirements for Establishing Phases 2, 3 and 4 of Financial Management Reform in the Health System From Interviewee's Point of View

\begin{tabular}{|c|c|c|}
\hline Themes & Sub-Scales & Some Selected Codes \\
\hline \multirow{3}{*}{ Economic requirements } & Efficient use of current capacity & \multirow{3}{*}{$\begin{array}{l}\text { Using unit net cost for services, Activity based cost of } \\
\text { health services, New budgeting techniques like } \\
\text { operational or functional ones, The ratio of health } \\
\text { system outputs and inputs, Economical scales in the } \\
\text { system }\end{array}$} \\
\hline & Operational budgeting & \\
\hline & Cost of services & \\
\hline \multirow{5}{*}{ Functional requirements } & Improved registration of operations & \multirow{5}{*}{$\begin{array}{l}\text { Transparency and relevancy of accounting, Integration } \\
\text { of financial and accounting processes, Transparency of } \\
\text { costing through better and exact recognition of costs, } \\
\text { Actual incomes because of on time recognition, } \\
\text { Operation and process documentation, Improving } \\
\text { internal audit and control by universities' auditors }\end{array}$} \\
\hline & Transparency of financial reports & \\
\hline & Effective internal control & \\
\hline & Standardization of processes & \\
\hline & Recognition of income and expenses & \\
\hline \multirow{4}{*}{ Legal requirements } & Financial regulation of universities & \multirow{4}{*}{$\begin{array}{l}\text { Annual reports of auditors, Reports presented for } \\
\text { managers' decision making, Financial and trading by } \\
\text { law of medical universities, Financial regulations at } \\
\text { different levels of MOHME and medical universities }\end{array}$} \\
\hline & Auditor's report & \\
\hline & Management notification & \\
\hline & Codification of regulations and guidelines & \\
\hline \multirow{2}{*}{ Organizational requirements } & Recruiting and training human resources & \multirow{2}{*}{$\begin{array}{l}\text { Improving staffing mechanisms, Recruitment of expert } \\
\text { accountants, Correction of human resources charts in } \\
\text { financial management of medical universities }\end{array}$} \\
\hline & Modernization of the organizational structure & \\
\hline \multirow{2}{*}{ Informational requirements } & Integrating of information & \multirow{2}{*}{$\begin{array}{l}\text { Using ROOZAMAD as a national software, Good } \\
\text { capabilities of reporting through integrated software }\end{array}$} \\
\hline & Software capabilities & \\
\hline \multirow{2}{*}{ Educational requirements } & In-service training & \multirow{2}{*}{$\begin{array}{l}\text { Training of staff accountants by new financial system } \\
\text { coaches }\end{array}$} \\
\hline & Cascade training & \\
\hline
\end{tabular}

considered as the most important economic requirement for financial reform in the health system.

In the Health and Medical Education field, effective financial management is more required than before, because of its different and wide activities span and its annual financial burden, according to the total public and private funds. An interviewee claimed that:

"Cash register and financial record of payments, order register of assets in the list of costs, weakness in financial reports, lack of financial statements and ambiguity of the budget led to the health organizations facing numerous problems that are caused by its identity as a governmental organization before financial reform (p12)".

\subsection{Functional Requirements}

Some of mentioned functional requirements were in the field of registry operation, transparency of financial reporting, internal control effectiveness, and standardization of processes as well as identify revenues and costs as the most important requirements for financial reform of the health system.

As mentioned above, other priorities were proposed by interviewees as follows: considering fund when cost or obligation occurred, existence and implementation of effective internal controls, consolidation and standardiza- tion of processes, activity-based budgeting, budgetary control, analysis of deviations from the plan, organizational structure, and homogenization of data.

Despite of the aforementioned problems, there are more functional requirements that make its conduction more necessary, such as the absence of strong world relations regarding information and the consequent poor decisions, and heterogeneity of information regarding human, logistics, finance, and budget resources as well as financial systems in health and medical organizations.

Increased efficiency and productivity, transparency, increased internal controls, evaluation of inventory accounting, receiving rapid, timely and detailed reports, optimal use of resources, showing quantities, and prevention of misuse are listed as the benefits of accrual accounting from participant's point of view. For example, an interviewee said that:

"In accrual accounting, financial reports, such as financial lists and operational level, should be prepared; also, the benefits of financial reports of accrual accounting are conformity of revenues and expenses during the year, measuring costs in the financial period and measuring revenue based on a financial period" (p3).

Functional requirements have been considered in the phase I in a form that the main purposes of accrual ac- 
counting implementation, in the participant's opinions, are transparency of accounts, providing comprehensive financial reports using calculation of cost of services and costs management, preparing aggregation financial statements of medical universities and health services, report on the periodic performance and its objectives, an enabling environment to provide a comprehensive budget, availability, development, completion and integration of eligible application software and a similar coding in all medical universities and its health services and subsidiary. An interviewee suggested that:

"Integration, possibility of monitoring and improving internal control using separation of the consumer items from capital items and providing an automatic accounting document, collecting inventory list and then, transition to the mechanized system, classification and coding of inventory and property in all units of the University, and, briefly, guidelines for property classification were also considered by the related decision-makers" (p21).

\subsection{Legal Requirements}

Interviewees believed that some of legal requirements to do financial reform are as follows: Fourth Development Plan (note 49, 88, 138 and 144), financial and transactional law in all medical schools and universities across the country, reform of note 63 and 64, public accounting law of the country, civil service management and the board of trustees laws, and the need to audit note 7 that was not implemented before the fourth developmental plan.

In this regard, a subject suggested that:

"After discussion with politicians and experts in several meetings at expert level, an unclear definition of the turnover framework of the fiscal and monetary operations, lack of cost management and productivity, guidelines and related laws and regulations, existence of accounting system, impossibility of cost, under representation of financial experts with relevant expertise and lack of an integrated coding system in the country were leading problems in the financial system, and also experts team concluded that financial information is not a decision-making basis" (p8).

Based on the experiences of the Ministry of Health, to establish and prepare legal requirements before phase I of reform, some actions were conducted, for example auditor certified by accountant's society of Iran began to work as an adviser of university president and supervisor of board of trustees in universities of medical science from year 2005 that was a very successful plan and audit reports were a basis for moving toward changes per year, and also provided internal and external policy-makers and planners with proper directions.

\subsection{Organizational Requirements}

These requirements are presented by interviewees as follows: health monetary comprehensive map, establishment of a comprehensive system (modifying financial organizational structure, recruiting financial experts, equipping and upgrading hardware and software, developing required guidelines), changes of accounting system in line with operational budgeting, and assessing the costs.

To move in line with these changes, the goal of information management consisted of financial independence and operational units accounting, modifying the cost of services, financial analysis of data and modern budgeting (tailored tools, planning, and efficient control), management accountability, and evaluation of management performance. Standardization and integration of financial processes, increasing appropriate internal controls regarding turnover of financial operations, exact costing to achieve cost services, continuous monitoring on turnover of financial operations in main organizations and subsidiaries and removing duplicate and parallel operation of financial process in main organization and subsidiaries must be considered by the planners to achieve financial independence and operational units accounting.

With regards to the aforementioned sentence, a participant described the seven steps of action to establish the first phase of reform in the field of financial management; 1) reform in the organizational structure of university finance, 2) setting memorandum between the main institution and subordinate units by managing budgets and allocating funds to the related sections, 3 ) issuing the closing document for the last year and closing the remained accounts in the last year and registry of the closing document in the new year by using a new financial software, 4) completing the closing document remaining from accounts of previous years, 5) registration of inventory turnover in a new financial software, 6) considering the principles and assumptions of accounting and guidelines of new financial system for diagnosing accounts to issue accounting documents in the form of accrual method, and 7) establishment of the accrual accounting system.

In this phase, identifying cost and operation centers will result in preparation of an integrated software, notification and teaching in the country, and given the approval of Board of Trustees of the universities and the faculty of medical sciences all around the country, this operation will comprehensively be run due torelevant regulations and guidelines across the universities of medical science.

Six steps were also introduced in the action plan of budget management to establish accrual accounting. In the first step, some plans will be implemented as complete familiarity with project (required components of the budget unit) with strategic and long-term approach, use of ex- 
periences and activities, familiarity with the instructions of new financial system, proficiency in the accounts structures in the new financial system and familiarity with new financial institutions.

\subsection{Informational Requirements}

To achieve these requirements, some necessary factors are needed, however, there are many informational shortcomings including lack of an experience in this regard in the governmental organization, geographical scope, numerous activities and services offered by universities and its subsidiaries, inappropriate organizational structure of finance, deficiency of skilled manpower, rules and regulations against the accounting standards, lack of a systematic relationship between the main organization and subsidiaries, unavailability of comprehensive financial software, lack of hardware facilities (computers and networks) and lack of hardware and software experts. An expert believed that:

"The primary focus of the auditor's report was on internal control that can be achieved by implementation of appropriate software systems (for mechanization), preparation of newspaper offices, income management(including income obtained by insurance and university), attention to conduct projects (providing project card and feasibility report), considering inventories (financial estimates of inventory and medication in stock and its record), correcting and detecting accounts (using registration and recognition of income, costs and remained funds in the system and study of stagnant items from previous years including payment and pre-payment) and management of assets (using identification and registration of ownership and detailed statement of assets)" (p18).

Also, another interviewee declared that:

"Many false conclusions are caused by the lack of information, not false judgment and the market of health services might be likely improved using coherent, comprehensive and integrated management interventions" (p6).

\subsection{Educational Requirements}

Announced educational requirements were as follows: better monitoring, evaluation and internal control, estimation of monetary assets, possibility of achieving the cost of services, possibility of implementing operational budgeting in the health and medicine sectors, determining the real cost, possibility of investment and cost and revenue management, administrative and financial autonomy, and, finally, improving the quality of health services and medical education. Also, they declared that all mentioned achievements may impose challenges including the costs of switching to accrual accounting such as training managers and changing the culture, software and hardware, choosing an expert accountant, long-term commitment of investment and providing a training package for financial management. An interviewee declared that:

"From the beginning of year 2009, to establish an integrated system in the main organization and its subsidiaries, some of the activities were done such as creating a new network connection, ordering and installing a server, and providing finance staff of main organization and its subsidiaries with appropriate hardware; then, the first and second part of the mentioned software were established from 2009 in all universities of medical science and the implementation of phase II was possible from 2011" (p15).

Participants also underlined the capacity of building human resources in a budget unit, upgrading staff, promoting experts, improving self-esteem of employees, providing necessary educational guidelines, training courses for employees, modernization of structures and processes, benefits from the innovation and technology, considering necessary regulations, reforms and instructions and determining new criteria for organization and its monitoring and evaluation as well as training in services. A subject announced that:

"To execute the first part of the reform, fifty trainers were educated that performed this project at a peripheral level of university of medical science" (p19).

\section{Discussion}

The present findings showed six requirements, including economic, functional, legal, organizational, informational, and educational factors as the most important priorities to implement and achieve the cost of health services, establish and implement operational budgeting, and achieve cost and efficiency management in the health system of Iran.

An assessment system of price of services in the health organizations plays an important role in evaluating health inventories and services cost in the recent years as seen in countries, such as Australia, Canada, Ireland, and Iceland (15). Moreover, a study conducted by quality assurance association of America in developing countries showed that activity-based costing is one of the most important methods for calculating the cost of services that can be used in health and medicine centers as an effective method (16). The present results could strongly show the requirements and prerequisites of the aforementioned method as the phase II of financial reform in the health system.

Furthermore, lack of adequate scientific information on the cost of services in governmental organizations has 
failed to implement the operational budgeting and principle 44 of constitution for privatization of activities in governmental organizations (17). However, necessary conditions are not provided for conducting the activity-based costing system due to poor knowledge of management, inability to identify activities required by costing, and inability to determine factors causing cost (18). Exclusively, resistance to change of finance and administrative staff, unfamiliarity of managers and experts with the technical issues of system, lack of management information system, lack of expertise in finance, and budget of organization and the ministry were also mentioned as other barriers to implement the cost services in the health system (19) that are associated with the current findings, emphasizing on functional requirements, such as registering operations, transparency of financial reporting, efficient internal control, process standardization, and identification of incomes and costs. Daneshfard and Shiranvand reported the lack of accrual accounting system and weakness in quantitative and proper indices for evaluating programs, as the most important obstacles for operational budgeting in the health system of the country. The authority and responsibility of managers and experts was more prioritized in the field of organizational structure. Weakness in costs system control was ranked as first in the financial management system. The highest rank in the human source criterion and functional requirements were respectively about staff resistance and poor regulations and internal guidelines for budgeting (20) that are significantly in relevance with the current findings.

Despite the implementation of financial reform in health system of the country, there are still problems in the conducting process that should be improved.

These findings with planning to identify and promote modifiable factors will provide the main policy-makers and decision-makers with comprehensive plans and will also support them to consider a long-term perspective. A study conducted by Bastani et al. revealed that interventions must be done considering 7 factors, including staff, managers, informational systems, organizational sub-culture, structures, processes and finance priorities to overcome the problems caused by phase I of reform, and also prepare a more appropriate condition to implement phases 2,3 , and $4(21,22)$.

It is recommended for managers and policy-makers to consider operational and formal guidelines to use the future phases of reform. Also, other techniques are suggested such as justifying and preparing employees for change and acceptance of the new system, practical training courses, using stimulus incentive, establishing an appropriate organizational culture to reform and solve the informational system problems.
The main administrative limitations of this study were as follows: the impossibility of interviewing with ministers of health after revolution as the key informants, and challenges in coordinating appointment for an interview with the health system decision-makers.

\subsection{Conclusion}

The findings showed that there are numerous problems and weak points for conducting financial reform, despite spending a decade after its implementation in the Iranian health system. Therefore, the current results as well as planning to recognize and promote the modifiable parts in this field might be likely beneficial to main policy-makers and decision-makers of the country to make a definite plan for revising this process with drafting a long-term perspective and a tailored context for complete and successful executing.

\section{Acknowledgments}

The authors wish to thank the Health Management and Social Development research center, Golestan University of Medical Sciences for approving and supporting this work with approval Number 35/394.

\section{References}

1. Abolhallaje M, Jafari M, Seyedin H, Salehi M. Financial Management Reforms in the Health Sector: A Comparative Study Between Cashbased and Accrual-based Accounting Systems. Iran Red Crescent Med J. 2014;16(10):e15472. doi: 10.5812/ircmj.15472. [PubMed: 25763194].

2. Bastani P, Vatankhah S, Salehi M, Dinarvand R. Strategic points of iranian health financial reform applying shanonn's entropy model. $J$ Appl Environ Biol Sci. 2013;3(10):81-7.

3. Arocena P, Garcia-Prado A. Accounting for quality in the measurement of hospital performance: evidence from Costa Rica. Health Econ. 2007;16(7):667-85. doi:10.1002/hec.1204. [PubMed: 17177284].

4. Abolhalaj M, Barati Marnani A, Bastani P, Ramezanian M, Jafari J. Ranking the strengths of Iranian health new financial management reform with approach of experts' attitude, group hierarchical analysis and Simple Additive Weighted model. Health Med. 2012;6(8):2871-7.

5. Abolhalaj M, Ramezanian M, Bastani P. Accrual accounting accomplishments in iranian universities of medical sciences: A mixed method study. Middle-East J Sci Res. 2012;12(3):294-300.

6. Lotfi F, Kalhor R, Bastani P, Shaarbafchi Zadeh N, Eslamian M, Dehghani MR, et al. Various indicators for the assessment of hospitals' performance status: differences and similarities. Iran Red Crescent Med J. 2014;16(4):e12950. doi: 10.5812/ircmj.12950. [PubMed: 24910796].

7. Abolhallaje M, Bastani P, Ramezanian M, Jafari J. Experts' analysis of the strengths of health system financial management reform in the first phase: A qualitative approach [In Persian]. Payavarde Salamat. 2013;6(6):423-33.

8. Hafezi R, Abolhallaje M, Ramezanian M. Designing new financial management system in health sector of Islamic Republic of Iran. Iran JPubl Health. 2009;38(1):173-8. 
9. Ouda H. Basic requirements model for successful implementation of accrual accounting in the public sector. Public Fund Digest. 2004;4(1):78-99.

10. Greene JK, Metwalli A. The impact of activity based cost accounting on health care capital investment decisions. J Health Care Finance. 2001;28(2):50-64. [PubMed: 11794757].

11. Abolhallaje M, Bastani P, Ramezanian M. Financial and transactional bylaw of universities and faculties of medical sciences: Opportunities and threats. Iran J Health Sci. 2013;1(3):1-11.

12. Adams JL, Smith JC, Strand B. Executing the double win: protect your cash flow during a patient accounting system install. Healthc Financ Manage. 2009;63(9):82-6. [PubMed:19743653] 88.

13. Safari S, Gholamrezaiee. D. . Designing Operating Budget in country executive organizations. Police Organ Dev J. 2006;3(8):3-42.

14. Bastani P, Mehralian G, Dinarvand R. Resource allocation and purchasing arrangements to improve accessibility of medicines: Evidence from Iran. J Res Pharm Pract. 2015;4(1):9-17. doi: 10.4103/2279042X.150045. [PubMed: 25710045].

15. Rajabi A, Dabiri A. Applying activity based costing (ABC) method to calculate cost price in hospital and remedy services. Iran J Public Health. 2012;41(4):100-7. [PubMed: 23113171].

16. Eldenburg L, Soderstrom N. Accounting system management by hos- pitals operating in a changing regulatory environment. Account Rev. 1996:23-42.

17. Foroghi D, Haghighi Parapari M, Rasaiian A. Feasibility of the implementation of activity-based costing (ABC) in operational budgeting of government agencies (a case study of government agencies of Isfahan Province) [In Persian]. QJ Health Account. 2012;1(1):47-62.

18. Abolhallaje M, Ramezanian M, Abolhasani N, Salarian Zade H, Hamidi $\mathrm{H}$, Bastani P. Iranian health financing system: challenges and opportunities. World Appl Sci J. 2013;22(5):662-6.

19. Rajabi A. Applying ABC system for calculating cost price of hospital services case study: Shahid Faghihi hospital of Shiraz [In Persian]. National Project Ministry Health Med Educ. 2005.

20. Daneshfard K, Shiravand S. Barriers of operational treatment budget in Islamic Republic of Iran, ministry of health and medical education [In Persian]. J Gorgan Univ Med Sci. 2012;14(2):90-6.

21. Bastani P, Abolhallaje M, Sadeghi A. Experts' analysis of the improvement spaces of health system financial management reform in the first phase: A qualitative approach [In Persian]. J Qazvin Univ Med Sci. 2016;20(1):47-55.

22. Abolhalaj M, Mousavi M, Jafari M. Implementation of financial management reforms in the health sector: Why it matters? J Health Policy Sustainable Health. 2014;1(4):113-4. 